\title{
Delayed Lower Urinary Tract Symptoms and Erectile Dysfunction after Acute Episode of Coccidioidal Meningitis
}

\author{
James H. Masterson ${ }^{\mathrm{a}}$ Mary F. Bavaro ${ }^{\mathrm{b}}$ Emily E. Cole \\ Naval Medical Center, Department of aUrology and 'blnfectious Diseases, Naval Medical Center, San Diego, Calif., USA
}

\section{Key Words}

Coccidioidal meningitis • Urinary urgency • Weak stream • Urinary frequency • Erectile dysfunction

\begin{abstract}
We present an interesting case of a 27-year-old male with coccidioidal meningitis who developed permanent erectile dysfunction (ED) and lower urinary tract symptoms 3 months after initiation of therapy. The patient presented to the urology clinic with a complaint of a weak stream, urinary urgency and frequency, as well as enuresis which were only moderately controlled with anti-cholinergics. His ED responded well to phosphodiesterase- 5 inhibitors. After an extensive review of the literature, this is the first report of delayed presentation of ED and lower urinary tract symptoms secondary to coccidioidal meningitis.
\end{abstract}

Copyright @ 2012 S. Karger AG, Basel

\section{Introduction}

Coccidioidomycosis is a fungal infection endemic to the southwestern United States with symptomatic disease occurring in approximately $30 \%$ of exposed patients. Most cases are either asymptomatic or pulmonary in nature, but approximately $5 \%$ of symptomatic diseased patients will have a systemic infection [1]. Rarely will it spread to the central nervous system where it was ultimately fatal until the advent of antifungal drugs in the 1950's [2].

\section{KARGER}

Fax +4161306 1234

E-Mail karger@karger.ch

www.karger.com
(C) 2012 S. Karger AG, Basel

1015-9770/12/0062-0109\$26.00/0

Accessible online at:

www.karger.com/cur

\section{Case Description}

Our patient is a 27 -year-old male who presented with several weeks of worsening headaches, myalgias, and nausea that progressively worsened, eventually requiring hospitalization. A lumbar puncture revealed greater than $800 \times 10^{3} / \mathrm{ml}$ white blood cells with $20 \%$ eosinophils. Coccidioides immitis was cultured from the cerebrospinal fluid (CSF). A head computed tomography (CT) and magnetic radiographic imaging (MRI) revealed no hydrocephalus or lesions.

He was treated with parenteral lipid complexed amphotericin $\mathrm{B}$ and high dose fluconazole (1,200 $\mathrm{mg}$ per os daily) for 3 weeks. Amphotericin B was stopped due to renal failure, hypokalemia, hypomagnesemia, and anemia; but fluconazole was continued. A chest x-ray and CT revealed pulmonary lymphadenopathy. His condition improved and was continued on high dose fluconazole with close outpatient follow-up. Three months after discharge, his CSF coccidioides immitis IgG complement fixation titer and enzyme linked immunosorbent assay were negative.

Two months after discharge from the hospital he developed minor urinary and bowel urgency including episodes of incontinence. Head and spine CT and magnetic radiographic imaging were normal without signs of arachnoiditis. A lumbar puncture revealed an opening pressure of $17.5 \mathrm{cmH}_{2} \mathrm{O}$, which was normal. Of note, he never had elevated lumbar puncture opening pressures throughout the course of his disease. His CSF was significant for 107 WBC (92\% lymphocytes), 1 RBC, glucose $39 \mathrm{mg} / \mathrm{dl}$, and protein $79 \mathrm{mg} / \mathrm{dl}$. A coccidioides immitis complement fixation titer was greatly improved, but marginally positive at 1:2.

He scored 28 out of 35 on the International Prostate Symptom Score; mostly significant for urgency, weak stream, incomplete voiding, and nocturia. Over the next month he also endorsed erectile dysfunction (ED), retrograde ejaculation, and decreased sensation of the penis glans. Median and ulnar electrodiagnostic testing revealed no abnormalities.

Serial lumbar puncture's over a 3-month course demonstrated normalization of his pleocytosis, glucose, protein and coccidioidal

James H. Masterson, MD

34800 Bob Wilson Dr

CA 92134, San Diego (USA)

Tel. +1 619 5327200, Fax +1 619 5327234, E-Mail James.masterson@med.navy.mil 


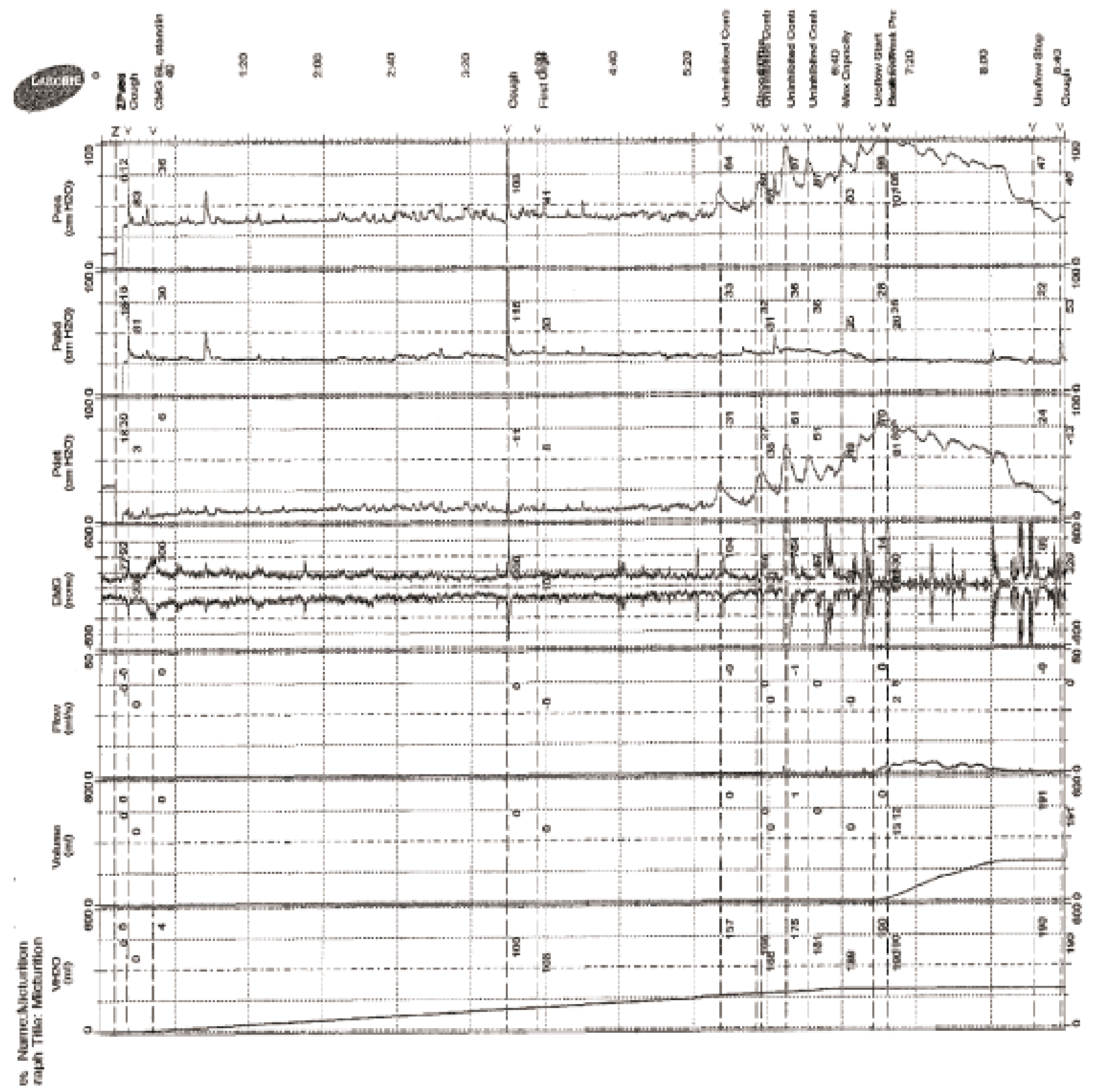

Fig. 1. Urodynamics demonstrate normal compliance with inhibited detrusor contractions beginning at $100 \mathrm{ml}$ and increasing in amplitude until terminating in a void at $190 \mathrm{ml}$. He voids with a maximum detrusor pressure of $77 \mathrm{cmH}_{2} \mathrm{O}$, maximum flow of $4.6 \mathrm{ml} / \mathrm{s}$, and post-void residual of $20 \mathrm{ml}$. His sphincter electyromyographic response showed appropriate guarding and relaxation when voiding. 
complement fixation titer. The patient had a history of a urethral catheter while undergoing initial treatment for meningitis, consequently a cystoscopy was performed evaluating for a stricture. The bladder neck was open and no strictures were seen. His fluconazole was changed to voriconazole due to headaches and dry skin.

A cystometrogram (fig. 1) showed normal compliance and uninhibited detrussor contractions with $175 \mathrm{ml}$ in his bladder. The contractions increased in amplitude until terminating in a void at $190 \mathrm{ml}$. A maximum flow of $4.6 \mathrm{ml} / \mathrm{s}$, peak detrusor pressure of 77 $\mathrm{cmH}_{2} \mathrm{O}$, and post-void residual of $20 \mathrm{ml}$ were observed. Electromyography showed normal guarding during the cystometrogram and relaxation of the bladder during voiding.

The patient reported increased flow with alfuzosin. Anticholinergic medications improved his urgency and frequency, but he was intermittently non-compliant because they exacerbated his ED. After 8 months the patient's symptoms stabilized with baseline ED and lower urinary tract symptoms. After nearly 2 years of following the patient he reports occasional urge incontinence and enuresis. He also requires phosphodiesterase-5 inhibitors to attain adequate erections. His bowel symptoms have resolved. $\mathrm{He}$ will require lifelong antifungal therapy to prevent relapse of infection.

\section{Discussion}

The acute symptoms of disseminated coccidioidomycosis are commonly characterized by headache, fever, nausea and vomiting. Symptoms of coccidioidal meningitis include headache, altered mental status to include personality changes, nausea, vomiting, and focal neurologic symptoms to include gait disturbances [2]. One third of patients may have hydroencephalus on CT imaging [3]. Acute symptoms typically resolve upon treatment of the disease however complications of meningitis may develop to include cerebral infarction related to vasculitis, spinal arachnoiditis, cerebral abscesses, and hyponatremia [2].

Current treatment consists of either high dose fluconazole or parenteral Amphotericin B followed by lifelong antifungal suppressive therapy given the high risk for relapse. High dose fluconazole remains the treatment option of choice for coccidioidal meningitis. Patients who fail conventional therapy may require intrathecal amphotericin, voriconazole or posaconzaole [2-4].

Meningitis has been associated with urinary retention, although it is rare [5]. Paraplegia and urinary retention are usually associated with hydrocephalus or arachnoiditis [2], but in our patient imaging was normal and his CSF normalized over several months. Arachnoiditis may be directly associated with the fungal meningitis but is also described as a result of intrathecal amphotericin. In a similar regard, ED has also been associated with meningitis, but usually due to sacral infection with herpes simplex virus.

Our patient never fully recovered normal bladder and erectile function, but he attained a baseline condition manageable with medications. He continued to have intermittent bouts of urgency as well as a weak stream. Despite a weak stream he did not have urinary retention. He was able to attain erections with phosphodiesterase-5 inhibitors, but never regained sensation of his glans penis. He will continue on lifelong anti-fungal treatment.

\section{Conclusion}

Coccidioidal meningitis is a rare entity that must be treated aggressively. Our patient is the first known case of delayed lower urinary tract symptoms and ED. These symptoms can be managed with medications to include anticholinergics and phosphodiesterase inhibitors.

The views expressed in this article are those of the author and do not reflect the official policy or position of the Department of the Navy, Department of Defense, or the United States Government.

\section{References}

1 Vinh DC: Coccidioidal meningitis: disseminated disease in patients without HIV/AIDS Medicine (Baltimore) 2011;90:87.

$>2$ Johnson RH, Einstein HE: Coccidioidal meningitis. Clin Infect Dis 2006;42:103-107.

3 Mathisen G, Shelub A, Truong J, Wigen C: Coccidioidal meningitis: clinical presentation and management in the fluconazole era. Medicine (Baltimore) 2010;89:251-284.

Coccidioidal Meningitis with LUTS and ED
4 Dewsnup DH, Galgiani JN, Graybill JR, Diaz M, Rendon A, Cloud GA, Stevens DA: Is it ever safe to stop azole therapy for Coccidioides immitis meningitis? Ann Intern Med 1996;124:305-310.
5 Fujita K, Tanaka T, Kono S, Narai H, Omori N, Manabe Y, Abe K: Urinary retention secondary to Listeria meningitis. Intern Med 2008;47:1129-1131. 